\title{
Mineração
}

\section{Perspectiva e potencial aplicação de biorreagentes na flotação de minerais}

\section{(Trends on the use of bioreagents in mineral flotation)}

\author{
Ana Elisa Casas Botero \\ DSc., Departamento de Ciência dos Materiais e Metalurgia, Pontifícia Universidade Católica \\ do Rio de Janeiro (Brasil) e Universidad Pontifícia Bolivariana Medellín (Colômbia) \\ E-mail: anaelisa@dcmm.puc-rio.br \\ Mauricio Leonardo Torem \\ DSc., Professor Associado, Departamento de Ciência dos Materiais e Metalurgia, \\ Pontifícia Universidade Católica do Rio de Janeiro.E-mail: torem@dcmm.puc-rio.br \\ Luciana Maria Souza de Mesquita \\ DSc., Agência Nacional do Petróleo - ANP.E-mail: Imesquita@anp.gov.br
}

\section{Resumo}

A flotação e floculação são práticas tecnológicas usadas na separação de minerais e suas aplicações têm aumentado nos últimos anos devido à flexibilidade e facilidade de operação, além de precisar de pouco espaço físico na instalação. (Torem \& Casquiera, 2003; Pearse, 2005).Uma das características da técnica de flotação é o emprego de regentes modificadores da superfície mineral. Esses reagentes tornam a superfície hidrofóbica e facilitam a separação. Em algumas ocasiões, esses reagentes podem apresentar inconvenientes de seletividade, custos elevados, além de alguns deles poderem se constituir em poluentes e apresentar sobrecustos no tratamento de efluentes do processo (Pearse, 2005). Atualmente, paralelamente ao emprego de reagentes convencionais, novas pesquisas estão sendo dirigidas para a produção de novos reagentes de flotação, a fim de que estes apresentem maior seletividade e não sejam agressivos ao meio ambiente, e não modifiquem o fluxograma do processo (Fuerstenau, 1999).Os microorganismos possuem paredes com macromoléculas de polímeros, proteínas, enzimas e ácidos orgânicos. Tem-se verificado que essas macromoléculas têm afinidade com diferentes sistemas minerais, modificando as propriedades da superfície, cumprem as mesmas funções dos reagentes convencionais de beneficiamento mineral (Namita \& Natarajan, 1999). O emprego de microorganismos no processo de separação mineral pode ser, então, chamado de Biobeneficiamento (Sharma \& Rao, 2003).

Esse artigo tem como objetivo apresentar as possibilidades e as características do biobeneficiamento mineral como uma nova alternativa na procura de novos reagentes nos processos de flotação e floculação.

Palavras-chave: Biobeneficiamento, bioflotação, biofloculação, biorreagentes.

\section{Abstract}

Flotation and Floculation are widely used for mineral separation. These unit operations use modifiers, collectors and depressants that modify the mineral surface properties. Some of these commercial reagents may be either expensive and / or inefficient for low grade ores (Torem \& Casquiera, 2003; Pearse, 2005). In recent years, several studies have been carried out on the use of microorganisms as friendly collectors. These microorganisms act as bioreagents and may induce hydrophobic properties, since they can adhere selectively to the mineral surface (Fuerstenau, 1999). The microrganism cell surface is conformed by functional groups like polymers, peptides, phospholipids, proteins and micolic acids (Namita \& Natarajan, 1999). These groups must adhere to the mineral surface directly and utilize cell surface associated or extracelular biopolymers to catalyze chemical reactions on the mineral surface. The Bioflotation and Bioflocculation processes are the use of micro-organism for the mineral separation. (Sharma \& Rao, 2003).

The aim of this article is to show the high possibility and characteristics of mineral biobeneficiation. The new process can be one alternative for looking for new reagents in flocculation and flotation processing.

Keywords: Biobeneficiement, bioflotation, bioflocculation, bioreactives. 


\section{Introdução}

As operações de flotação e floculação são utilizadas, tradicionalmente, na separação seletiva de minerais. Essas operações utilizam reagentes comercias de tipo anfipático, que modificam as propriedades da superfície mineral e facilitam sua separação. Alguns desses reagentes podem ser de custo elevado ou podem ser ineficientes para a separação seletiva de minerais de baixo teor (Torem \& Casquiera, 2003; Pearse, 2005; Fuerstenau, 1999; Namita \& Natarajaan, 1999; Sharma \& Rao, 2003).

O processo chamado de Biobeneficiamento é uma técnica que emprega microorganismos na separação seletiva dos minerais, constituindo-se em um processo rápido, que envolve modificações nas propriedades da superfície do mineral mediante a adesão microbiana. Nesse processo, os microorganismos atuam como biorreagentes do tipo coletores ou de modificadores que transformam a superfície hidrofílica do mineral em um composto com características hidrofóbicas, facilitando, assim, a separação nas operações convencionais de flotação e/ou floculação.
Alguns microorganismos em função da presença de grupos funcionais de polímeros, carboidratos, proteínas e ácidos micólicos presentes em sua parede celular, conferem aos mesmos propriedades que os tornam capazes de atuar como biorreagentes (Van der Wal et al., 1997). Esses grupos podem interagir com a superfície mineral e conferir-lhe características anfipáticas da mesma maneira que os reagentes usados tradicionalmente no processamento mineral (Mesquita et al., 2003. Alguns microorganismos têm sido usados como biorreagentes para a separação de alguns sistemas minerais. A Tabela 1 mostra alguns exemplos.

No Biobeneficiamento é importante estudar as propriedades superficiais do microorganismo e sua interação com a superfície mineral. Propriedades como a carga superficial e hidrofobicidade do microorganismo, e tensão de energia interfacial, assim como a presença e configuração de polímeros na parede celular, ajudam na compreensão dos mecanismos de adsorção e adesão sobre a superfície mineral. (Norde et al., 1997, Poortiga, 2002).

\section{Características dos microorganismos no biobeneficiamento de minerais}

\section{Configuração da parede celular}

Mecanismos diretos e indiretos são utilizados pelas bactérias para modificar a superfície do mineral. Os mecanismos diretos implicam a adesão das células à superfície. Os indiretos se dão via o emprego de compostos produzidos a partir dos microrganismos que interagem com a superfície mineral, modificando suas propriedades físico-químicas (Mesquita, 2000).

A parede celular é composta, principalmente, de polímeros como peptídeoglicana, além de substâncias poliméricas extracelulares (EPS), fosfoglicerídeos, fosfolipídeos, proteínas e ácidos orgânicos como ácido micólico (Norde et al., 1997). A composição da parede celular determina a capacidade de as bactérias de se aderirem aos diferentes tipos de superfícies. A Figura 1 apresenta a con-

Tabela 1 - Microorganismos usados em sistemas minerais.

\begin{tabular}{|c|c|c|c|}
\hline Sistema mineral & Microorganismos & Função do Reagente & $\begin{array}{c}\text { Referência } \\
\text { Bibliográfica }\end{array}$ \\
\hline $\begin{array}{l}\text { Flotação de calcita / hematita } \\
\text { coríndon quartzo }\end{array}$ & Bacillus polymyxa & $\begin{array}{l}\text { Depressor para } \\
\text { coríndon quartzo }\end{array}$ & $\begin{array}{c}\text { Namita \& Natarajan, } \\
1999 .\end{array}$ \\
\hline $\begin{array}{c}\text { Floculação de finos de } \\
\text { hematita }\end{array}$ & Mycobacterium phei & Agente floculante & Dubel et al, 1992. \\
\hline Hematita /quartzo & Bacillus polymyxa & $\begin{array}{l}\text { Depressor para } \\
\text { hematita }\end{array}$ & Dubel et al, 1992. \\
\hline Hematita / quartzo & Rhodococcus opacus & Coletor para hematita & Mesquita, 2000. \\
\hline Dolomita / apatita & $\begin{array}{l}\text { Mycobacterium phei, } \\
\text { Bacillus subtillis }\end{array}$ & $\begin{array}{c}\text { Depressor para } \\
\text { dolomita }\end{array}$ & Sheng et al, 2001. \\
\hline $\begin{array}{c}\text { Pirita de óxidos minerais } \\
\text { (pirita, quartzo, pirita, calcita) }\end{array}$ & Bacillus polymyxa & $\begin{array}{l}\text { Depressor para } \\
\text { hematita }\end{array}$ & $\begin{array}{c}\text { Patra \& Natarajan, } \\
2003 .\end{array}$ \\
\hline $\begin{array}{l}\text { Pirita, calcopirita, sulfeto de } \\
\text { cobre. }\end{array}$ & Acidithiobacillus ferroxidans & $\begin{array}{c}\text { Coletor de sulfeto de } \\
\text { cobre }\end{array}$ & Hosseine, 2004. \\
\hline Pirita / calcopirita & $\begin{array}{l}\text { Acidithiobacillus ferroxidans, } \\
\text { Ácidibacillus thioxidans }\end{array}$ & Coletor para galena & Natarajan \& Das, 2003. \\
\hline $\begin{array}{l}\text { Flotação de Magnesita } \\
\text { Calcita }\end{array}$ & Rhodococcus opacus & Coletor & Botero et al, 2007. \\
\hline
\end{tabular}


formação da parede celular de uma bactéria contendo ácido micólico.

Namita e Natarajan (1997) estudaram o comportamento dos polissacarídeos extracelulares e proteínas de células de B. polymyxa na presença dos minerais de calcita, hematita, coríndon e quartzo. Foi observado que a interação de B. polymyxa com os minerais levou a mudanças significativas na superfície dos mesmos. Quartzo tornou-se mais hidrofóbico, enquanto que calcita, hematita, coríndon tornaram-se mais hidrofílicos. Essas mudanças são atribuídas à maior afinidade dos minerais pelas moléculas presentes na parede celular. No caso de quartzo, ele tem maior afinidade por moléculas de proteínas, as quais são mais hidrofóbicas. No caso da calcita, hematita e coríndon, eles têm maior afinidade pelos polissacarídeos, os quais tem características hidrofílicas.

A presença dos compostos protéicos e poliméricos na superfície celular pode ser modificada dependendo das condições nutricionais na cultura do microorganismo. A carência de alguns nutrientes essenciais no meio de crescimento, assim como a presença do alguns compostos específicos, pode ativar o metabolismo dos microorganismos para a produção de diferentes moléculas na parede celular (Anand et al., 1996, Pelczar, 1993).

\section{Carga elétrica dos microorganismos}

Quando a partícula se encontra num meio aquoso e é submetida a um campo elétrico, irá apresentar um movimento, positivo, negativo ou neutro, dependendo das características aniônicas ou catiônicas da superfície.

Dependendo da presença de determinados grupos funcionais presentes na superfície, estabelece-se o comportamento total da carga. Essa característica vai depender da espécie e das condições de cultivo. Tem-se verificado que a presença de polissacarídeos determina um comportamento mais aniônico devido aos grupos fosfatos. A presença de áto- mos de nitrogênio nas proteínas e aminas confere um comportamento mais catiônico à superfície (Mozes et al., 1989). A predominância de determinados grupos funcionais, na parede da célula microbiana, e a interação entre eles vão conferir carga negativa ou positiva à superfície do microorganismo. Essa característica vai depender da espécie e das condições de cultura.

As modificações nas características da superfície mineral decorrente da adesão com as células estão relacionadas com a interação dos grupos hidroxila dos EPS e dos grupos amidos das proteínas da parede celular, que interagem com os grupos da superfície mineral através de pontes de hidrogênio e ligações químicas, dependendo do tipo de mineral e das condições do meio aquoso (Shashikala \& Raichur, 2002).
A carga da superfície pode ser estabelecida pelo potencial zeta. Essa medida determina o caráter global da superfície para diferentes valores de $\mathrm{pH}$. O valor de $\mathrm{pH}$ onde se anulam as cargas e apresenta-se reversibilidade (potencial zeta nulo) é chamado de ponto isoelétrico (PIE) e indica as características catiônicas ou aniônicas da superfície do microorganismo (Sharma et al., 2003; Rijnaarts et al., 1995).

Geralmente, o PIE do microorganismo tem tendência a ser negativo devido à predominância dos grupos fosfatos sobre os grupos amidos presentes na parede celular (Mozes et al., 1989). A Tabela 2 mostra diferentes espécies de bactérias com diferentes valores de PIE (Waltermann et al., 2005).

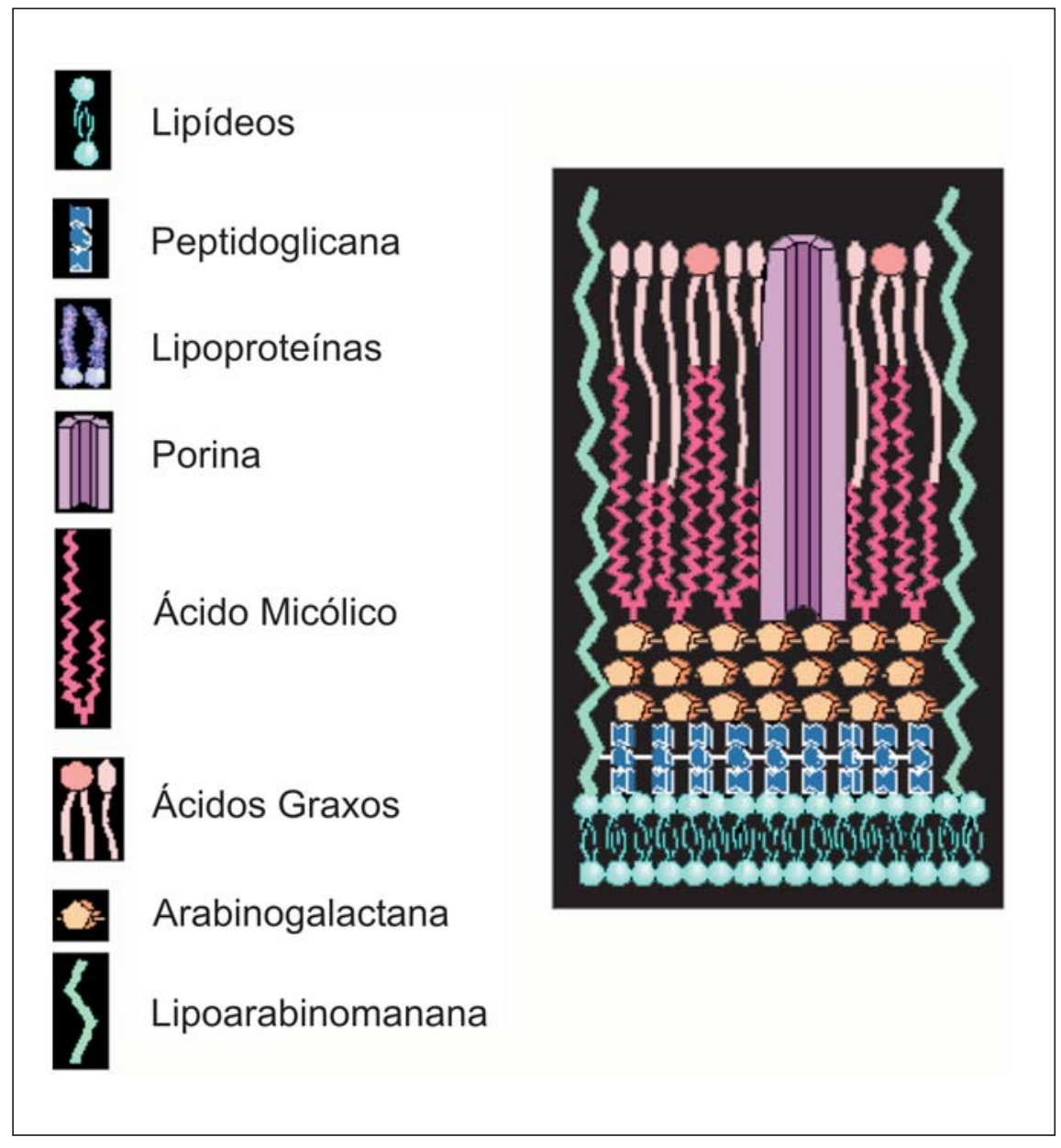

Figura 1 - Conformação da parede celular de bactérias contendo ácido micólico. (Pelczar, 1993). 
Tabela 2 - Valores de PIE para diferentes espécies de bactérias (Waltermann et al., 2005).

\begin{tabular}{l|c}
\hline \multicolumn{1}{c|}{ Tipo Bactéria } & PIE \\
\hline Arthobacter $s p$ & 1,7 \\
\hline Pseudomona olecorants & 1,7 \\
\hline Pseudomonas $s p$ & 2,2 \\
\hline Pseudomonas putida & 3,2 \\
\hline Coryneform $s p$ & 2,6 \\
\hline Rhodococcus erytropolis & 2,8 \\
\hline Rhodococus $s p$ & 3,0 \\
\hline Gordona $s p$ & 3,4 \\
\hline
\end{tabular}

A presença de polieletrólitos, assim como as variações do $\mathrm{pH}$, permite a ativação dos grupos funcionais presentes nas paredes dos microorganismos. Isto conduz a maior ou menor aderência ao mineral.

A afinidade da bactéria com a superfície mineral depende, em grande parte, da força iônica da solução aquosa, assim como a variação do $\mathrm{pH}$. Esses fatores determinam a ativação dos grupos funcionais presentes na parede dos microorganismos, conduzindo a uma maior ou menor aderência à superfície mineral.

Mesquita et al. (2003)[9] estudaram a interação de $R$. opacus e partículas de hematita e quartzo em presença de $\mathrm{NaCl}$ como polieletrólito. Nesse estudo, o microorganismo aderiu às superfícies de quartzo apenas em uma faixa de $\mathrm{pH}$ ácida entre 2,8 e 4,0. Para a hematita, os valores de $\mathrm{pH}$ que favoreceram a adesão corresponderam a uma faixa entre 5,0 e 11. Esses resultados apresentam uma seletividade de adesão em função dos valores de $\mathrm{pH}$ empregados.

\section{Caráter anfipático dos microorganismos}

Outra característica dos microorganismos é seu caráter anfipático, ou seja, sua capacidade de apresentar caracte-
Tabela 3 - Valores de ângulos de contato para diferentes microrganismos (Van de Mei \& Busscher, 1998).

\begin{tabular}{l|c}
\hline \multicolumn{1}{c|}{ Tipo de Bactéria } & Ângulo de Contato $\theta$ (Graus) \\
\hline Arthobacter $s p$ & 15 \\
\hline Pseudomona flourecens & 25 \\
\hline Rhodococous $s p$ & 70 \\
\hline Coryneobacterium $s p$ & 89 \\
\hline Gordona & $103^{*}$ \\
\hline
\end{tabular}

rísticas hidrofóbicas e hidrofílicas. A hidrofobicidade é a propriedade de as moléculas serem repelidas da superfície aquosa. Essa característica vai depender da interação dos grupos apolares e polares presentes na parede microbiana.

A hidrofobicidade das células microbianas apresenta grande variação dependendo da proporção de grupos graxos de sua parede. Os grupos funcionais hidrofóbicos e o caráter ácido ou básico da superfície celular determinam as características anfipáticas (Mesquita, 2000). Um microorganismo que apresentar uma superfície hidrofóbica e que for capaz de aderir à superfície do mineral pode tornar essa hidrofóbica e, assim, promover a flotação do mineral. Nesse caso, o microorganismo poderá atuar como coletor.

A medida de ângulo de contato determina a preferência dos microorganismos pelas bolhas de ar; quanto maior o ângulo de contato, maior é a hidrofobicidade. Essa propriedade vai depender das espécies microbianas (Smith \& Miettinem, 2006). Van der Mei et al. (1998) compilaram da literatura valores de ângulo de contato para um total de 142 espécies microbianas, incluindo bactérias, leveduras e actinomicetes, com graus de hidrofobicidade variando de $15^{\circ}$ a $100^{\circ}$. A Tabela 3 apresenta diferentes valores de ângulos de contato para microorganismos de diferentes espécies.

\section{Conclusões}

O desenvolvimento de biorreagentes para a separação seletiva de minerais tem sido objeto de recentes pesquisas. O interesse em trabalhar com microorganismos que sejam seletivos para minerais é cada vez maior e é crescente o estudo fundamental referente a esse tema.

Os trabalhos apresentados nesse artigo indicam a necessidade de encontrar microorganismos seletivos com a capacidade de interação com diferentes minerais dependendo do interesse comercial de cada país. Desse modo, mesmo com o aumento no interesse de estudar biorreagentes, existem, ainda, muitos desafios que devem ser superados, tais como problemas como a produção do microorganismo, a dose de biorreagentes e as avaliações econômicas. Todas essas questões devem ser consideradas na hora de produzir biorreagentes para os processos de flotação e floculação (Van de Mei \& Busscher, 1998).

\section{Referências bibliográficas}

ANAND, B. et al. Biobeneficiation of bauxite using Bacillus polymyxa: calcium and iron removal. International Journal of Mineral Processing, v. 48, p. 51-60, 1996. 
Ana Elisa Casas Botero et al.

BOTERO, C.A.E., TOREM, M.L., MESQUITA, L.M.S. Fundamental studies of Rhodococcus opacus as a biocollector of calcite and magnesite. Minerals Engineering, v. 20, p. 10261032, 2007.

DUBEL, J., SMITH,R. W., MISRA, M., CHEN, S. Microorganisms as chemical reagents: The hematite system. Minerals Engineering, v. 5, n. 3-5, p. 547-556, 1992.

FUERSTENAU. Froth flotation the first ninety years. Advances in Flotation Technology, USA Ed. Parket and J. D. Miller, 1999. 463p.

HOSSEINI et al. Bioflotation of Sarcheshmeh copper ore using Thiobacillus ferroxidans bactéria. Minerals Engeneering, Online 2004.

MESQUITA, L.M.S. Bioflotação de hematita e quartzo - um estudo de seletividade. Rio de Janeiro: PUC-Rio, 2000. 93p. (Tese de Doutorado).

MESQUITA, LINS, F.F., TOREM, M.L., Interaction of a hydrophobic bacterium strain in a hematite - quartz flotation System. International Journal of Mineral Processing, v. 71, p. 31-44, 2003.

MOZES, N., AMORY, D., LEONRD, A., ROUXHET. Surface Properties of Microbial Cells and their Role in Adhesion and Flocculation. Colloids and Surfaces, v. 42, p. 313-329, 1989.

NAMITA DEO, NATARAJAN, K.A. Role of Corundum - Adapted Strains of Bacillus polymixa in the separation of hematite and alumina. Minerals \&
Metallurgical Processing, v. 16, n. 4, p. 29-34, 1999.

NATARAJAN, K.A, DAS, A. Surface chemical studies on 'acidithiobacillus' group of bacteria with reference to mineral flocculation. International Journal of Mineral Processing, v. 72, p. 189-198, 2003.

NORDE A., A.J.B. ZEHNDER, B., LYKLEMA J. A Determination of the total charge In the cell walls gf grampositive bacteria. Colloids and Surfaces B: Biointerfaces, v. 9, p. 81-100, 1997.

PATRA, P., NATARAJAM, K.A. Microbially - Induced flocculation and flotation for pyrite separation from oxide gangue minerals. Minerals Engineering, v. 16, p. 965-973, 2003.

PEARSE, M. J. N. A overview of the use of chemical reagentes. Mineral Processing, v. 18, p. 139-149, 2005.

PELCZAR, M. J., CHANG, E., KRIEG, N. Microbiology concepts and application. New York: Mc Graw Hill, 1993. 897 p.

POORTIGA, A., BOSS, R., NORDE, W., BUSSHER, H. Electric double layer interactions in bacterial adhesion to surfaces. Surface Science Reports, v 47, p 1-32 2002.

RIJNAARTS, $\mathrm{H}$. et al, Reversibility and mechanism of bacterial adhesion. Colloids and Surfaces B: Biointerfaces, v. 4, p. 5-22, 1995.

SHARMA, A., DASB, K., HANUMANTHA RAO, K.S.E., FORSSBERG. Surface characterization of acidithiobacillus ferrooxidans cells grown under different Conditions. Hydrometallurgy, v 71, p. 285-292, 2003.
SHARMA, P. K., HUNUMANTHA RAO K. Adhesion of Paenibacillus polymixa on chaocopyrite and pyrite: surface thermodynamics and extended DLVO theory. Colloids and Surfaces B: Biointerfaces v. 29, p. 21-38, 2003.

SHASHIKALA, A., RAICHUR, A. Role of interfacial phenomena in determining adosrption of bacillus polymixa onto hematite and quartz. Colloids and Surfaces B: Biointerfaces, v. 24, p. 1120, 2002.

SHENG, X., ARPS, P. J., SMITH, R. W. Adhesion of two bacteria onto dolomite and apatite: their effect on dolomite depression in anionic flotation. International Journal of Mineral Processing, v. 62, p. 159-172, 2001.

SMITH, R.W., MIETTINEM, M. Microorganisms in flotation and flocculation: Future technology or laboratory curiosity? Minerals Engineering, v. 19, p. 548-553, 2006.

TOREM, M.L., CASQUIERA, R. Flotação aplicada à remoção de metais pesados. Rio de Janeiro: Série Tecnologia Ambiental CETEM, 2003. 30 p. (No 28)

VAN DER MEI, H. C., BOS, R. BUSSCHER, H.J. A reference guide to microbial cell surface hidrophobicity based on contact angles. Colloids and Surfaces B: Biointerfaces, v. 11, p. 213-221, 1998.

WÄLTERMANN et al. Mechanism of lipidbody formation in prokaryotes:how bacteria fatten up. Molecular Microbiology, v. 55, n.3, p. 63, 2005.

\section{Artigo recebido em 31/05/2006 e} aprovado em 18/09/2007.

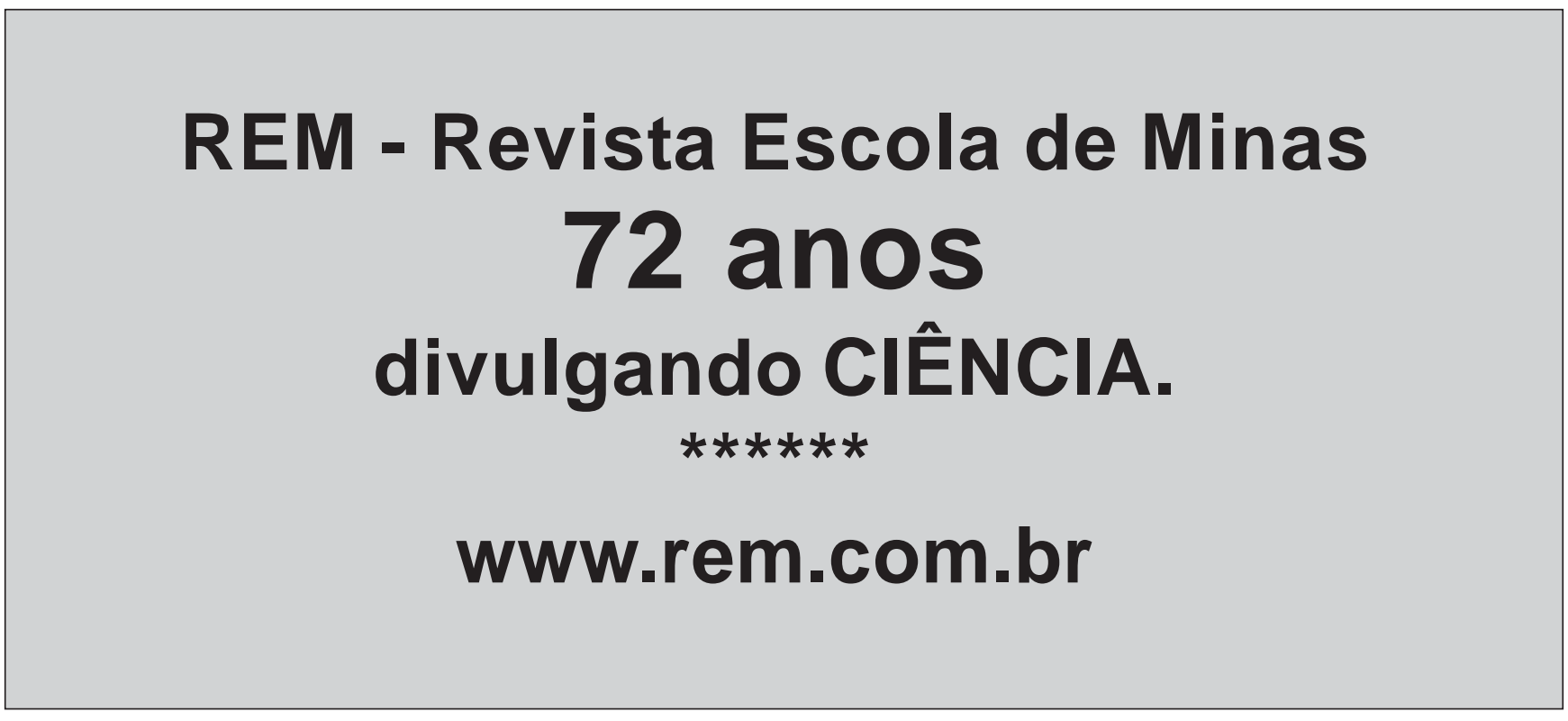

